\title{
Factors Impacting Range Hood Use in California Houses and Low-Income Apartments
}

\author{
Haoran Zhao ${ }^{1} ®$, Wanyu R. Chan ${ }^{1} \oplus$, William W. Delp ${ }^{1}$, Hao Tang ${ }^{2}$, Iain S. Walker ${ }^{1}($ and \\ Brett C. Singer ${ }^{1, *(D)}$ \\ 1 Indoor Environment Group and Residential Building Systems Group, Lawrence Berkeley National \\ Laboratory, Berkeley, CA 94720, USA; haoranzhao@lbl.gov (H.Z.); wrchan@lbl.gov (W.R.C.); \\ wwdelp@lbl.gov (W.W.D.); iswalker@lbl.gov (I.S.W.) \\ 2 National Centre for International Research of Low-Carbon and Green Buildings, Ministry of Science and \\ Technology, Chongqing University, Chongqing 400045, China; haotang1994@cqu.edu.cn \\ * Correspondence: bcsinger@lbl.gov
}

Received: 5 September 2020; Accepted: 22 November 2020; Published: 28 November 2020

\begin{abstract}
Venting range hoods can control indoor air pollutants emitted during residential cooktop and oven cooking. To quantify their potential benefits, it is important to know how frequently and under what conditions range hoods are operated during cooking. We analyzed data from 54 single family houses and 17 low-income apartments in California in which cooking activities, range hood use, and fine particulate matter $\left(\mathrm{PM}_{2.5}\right)$ were monitored for one week per home. Range hoods were used for $36 \%$ of cooking events in houses and $28 \%$ in apartments. The frequency of hood use increased with cooking frequency across homes. In both houses and apartments, the likelihood of hood use during a cooking event increased with the duration of cooktop burner use, but not with the duration of oven use. Actual hood use rates were higher in the homes of participants who self-reported more frequent use in a pre-study survey, but actual use was far lower than self-reported frequency. Residents in single family houses used range hoods more often when cooking caused a discernible increase in $\mathrm{PM}_{2.5}$. In apartments, residents used their range hood more often only when high concentrations of $\mathrm{PM}_{2.5}$ were generated during cooking.
\end{abstract}

Keywords: indoor air quality; cooking pollutants; kitchen ventilation; occupant survey; particulate matter; nitrogen dioxide; exposure mitigation

\section{Introduction}

Cooking is one of the largest sources of air pollutant emissions inside many homes. Gas cooking burners emit carbon monoxide $(\mathrm{CO})$, nitrogen dioxide $\left(\mathrm{NO}_{2}\right)$, formaldehyde $(\mathrm{HCHO})$ and ultrafine particles and electric burners emit ultrafine particles in substantial quantities [1-7]. $\mathrm{NO}_{2}$ from gas cooking burners may commonly result in indoor concentrations that exceed the threshold of $100 \mathrm{ppb}$ over $1 \mathrm{~h}$ that is used in the U.S. ambient air quality standard [8,9]. Belanger et al. [10] reported that exposure to higher levels of residential $\mathrm{NO}_{2}$ was associated with asthma severity and a meta-review by Lin et al. [11] found that gas cooking and higher $\mathrm{NO}_{2}$ exposure were each associated with increased risk of asthma and higher $\mathrm{NO}_{2}$ was associated with current wheeze. High temperature cooking activities (e.g., frying and broiling) contribute odors and pollutants including hazardous organic gases, polycyclic aromatic hydrocarbons, and fine and ultrafine particles [12-20]. In addition to the health effects associated with higher exposures to these pollutants (e.g., [21]), a study in Hong Kong [22] reported a dose-response relationship between lifetime exposure to cooking fumes and lung cancer. Both gas burners and cooking generate water vapor that may contribute to excess indoor moisture and associated problems if not adequately managed [23]. 
Venting range hoods and combination "over the range" (OTR) microwave/exhaust fans mounted above the cooktop are designed to remove some fraction of the emitted pollutants to outdoors before they mix into the air volume of the kitchen and throughout the home. Several modeling and experimental studies have examined the effectiveness of range hood use to reduce cooking-related indoor air pollution $[5,8,9,24-30]$.

It is not clear how many US homes have venting range hoods because their presence has not been investigated in large surveys of home appliances [31,32]. Published data from indoor air quality (IAQ) surveys indicate that venting range hoods are installed in many homes in California. For instance, a study of 644 low-income Latina households in Salinas found that $65 \%$ of the homes with gas stoves were equipped with functional kitchen ventilation devices [33]. A survey-based study of 1448 detached houses built in 2003 reported that $80 \%$ had range hoods exhausting to outdoors and $4 \%$ had downdraft ventilators, while $13 \%$ had recirculating range hoods and $3 \%$ had no range hood or did not know [34]. A recent survey of occupants in 2781 homes built since 2003 and that have gas cooking burners found that $76 \%$ had a venting kitchen range hood or OTR, $12 \%$ had a recirculating range hood or OTR, and $4 \%$ reported not knowing what they had [35]. While we did not find data reported for large IAQ studies from other US states, the authors understand from discussions with building professionals throughout the US that the presence of kitchen ventilation varies both across and within states.

Venting range hoods are required in several building codes and standards. For example, ANSI/ASHRAE Standard 62.2 for residences requires a minimum on-demand airflow rate of $50 \mathrm{~L} / \mathrm{s}$ or $100 \mathrm{cfm}$ at a maximum sound rating of 3 sones [36]. The Energy Star program requires kitchen ventilation consistent with Standard 62.2 and additionally requires a minimum efficiency of $2.8 \mathrm{cfm} / \mathrm{W}$ and a maximum sound level of 2.0 sones for range hoods with power consumption less than 75 Watts [37]. Though venting range hoods are not required by the International Mechanical Code [38] or International Energy Conservation Code [39], they are required by many US states and cities. Starting with the 2007 update to the Title 24 Building Code-specifically in the Building Energy Efficiency Standards (BEES) that comprise Part 6 of the Code-California has required all newly constructed residences and major renovations to have kitchen ventilation equipment in concordance with the requirements of Standard $62.2[40]$.

Venting range hoods help with IAQ management only if they are used when cooking occurs [5,41]. To quantify IAQ benefits from using range hoods, it is important to know how frequently and under what conditions they are operated during cooking. In many studies, range hood use has been estimated based on participant self-reporting. Studies have inquired of generic use (yes/no) and sometimes queried the frequency or reasons for using or not using the devices. For example, in the study of 1448 detached houses in California built in 2003, 28\% of survey respondents reported using a kitchen exhaust fan when cooking with cooktop burners but only $15 \%$ reported exhaust fan use when cooking with an oven [34]. In the web-based survey of occupants in 2781 California homes built since $2003,34 \%$ of households reported using their range hoods during cooking always or most of the time, 30\% reported occasional (sometimes) use and 32\% reported rarely or never using a hood [35]. In another California study, $34 \%$ of 372 homes reported using their range hoods during cooking, with higher frequencies during dinner and more use with longer cooking duration [42]. Higher resolution information on self-reported range hood use is available from daily activity logs recorded in some IAQ studies. In a study of 132 Canadian homes, Liu and Wallace found that only $13 \%$ of households reported range hood use during cooking events in winter and use decreased to $10 \%$ of cooking events in summer [43].

The goal of the study reported here was to assess actual range hood use based on monitoring of cooking activities and range hood operation in occupied homes. This study presents an analysis of data collected over weeklong periods in 54 houses and 17 apartments which were recently constructed or renovated in California. Data were analyzed to determine the frequency of range hood use during part or all of the cooking events with a focus on the effects of the following parameters: (1) cooking burner(s) used (cooktop, oven or both); (2) home type (house or apartment); (3) range hood type (conventional hood or OTR); (4) cooking duration (minutes of burner use); (5) self-reported usage; and 
(6) fine particulate matter $\left(\mathrm{PM}_{2.5}\right)$ emissions during cooking. We also investigated whether the rate of range hood use in a home was associated with any household or equipment characteristics.

\section{Materials and Methods}

\subsection{Overview of Data Collection}

This study used data collected from two recent field studies of ventilation and indoor air quality in California homes with natural gas cooking appliances. All homes had natural gas cooktop burners and at least one oven, but some ovens were electric. All homes had venting range hoods and dwelling unit mechanical ventilation systems installed to satisfy state building code requirements. The Healthy, Efficient New Gas Homes (HENGH) study collected data in 2016-2018 in 70 single, detached houses that were built in 2011-2017 [35,44,45]. A second study collected data in 2018-2019 in 23 apartment units at 4 properties constructed or renovated in 2013-2017 [46,47]. The apartments were occupied by income-qualifying households and participants affirmed that they used their gas cooking burners on a daily or almost daily basis. HENGH homes had a mix of venting range hoods $(n=32)$ and OTRs $(n=38)$. All apartments had a venting range hood.

Each home was monitored for a one-week period and the residents were requested to keep windows closed and the dwelling unit mechanical ventilation system operating. Based on window monitoring and participant entries to daily activity logs, significant natural ventilation was used in only a small fraction of the houses and at least 5 of the 23 apartments. A number of indoor air pollutants were measured, including time-resolved fine particulate matter $\left(\mathrm{PM}_{2.5}\right) . \mathrm{PM}_{2.5}$ concentrations were measured at 1-min logging intervals indoors and outdoors using MetOne photometers (Model BT-645 and ES-642) for houses, and 2-min logging intervals using DustTrak photometers (TSI Model 8530) for apartments. Operation of the cooktop and oven were monitored at 1.5-min intervals with iButton sensors (Maxim DS1922T) that were arranged on cooktops to enable detection of temperature changes caused by each burner, and at the oven vent. Range hood usage was monitored at 1-min intervals using a logging anemometer (Digisense WD-20250-22) placed at the air inlet or using a motor on-off logger (Onset HOBO UX90-004) placed close to the motor. Residents were asked to record occupancy and activities throughout each day of monitoring using a daily log sheet. A participant from each home completed a survey that asked about household demographics, satisfaction with environmental conditions in the home, use of ventilation equipment, and other activities that can impact IAQ. The surveys asked how often range hoods were used during cooktop use (for houses) or any cooking events (for apartments). Both of the field studies were conducted using protocols approved by the Lawrence Berkeley National Laboratory Human Subjects Committee.

The two field studies contributing data to this research were approved by Lawrence Berkeley National Laboratory's institutional review board following US government regulations for research involving human subjects; the house study was protocol 318H003 approved 5/12/2015 and the apartment study was protocol $280 \mathrm{H} 013$ approved 11/19/2018.

\subsection{Cooking Burner Events}

Temperature data recorded by iButtons were analyzed to identify individual burner use events with specified start and end times. The start of a cooking event was identified by a rapid rise in temperature (Figure 1). A distinct threshold rate of temperature rise was specified to identify the start of cooking events in each home. Most thresholds were in the ranges of 0.6 to $1{ }^{\circ} \mathrm{C} / \mathrm{min}$ for cooktop burners and 0.6 to $2{ }^{\circ} \mathrm{C} / \mathrm{min}$ for ovens. The end of a cooking event was designated as the time when the burner temperature started to drop, with most decays being between 0.2 and $0.5^{\circ} \mathrm{C} / \mathrm{min}$. Selection of the threshold value for each home was done by visual inspection.

Individual burner events that overlapped in time, or consecutive events that ended and started within 3 min of one another, were grouped into multi-burner cooking events. Each cooking event is defined by a start and stop time, burners used (CT for cooktop only, OV for oven only and CTOV 
for both), total minutes of CT burner use (e.g., 2 CT burners used for 10 min each is 20 burner-min) and total minutes of all burner operation. This includes the estimated full duration of OV use, not accounting for cycling of the OV burner. In some analyses, the term "any CT" is used to refer to cooking events involving cooktop burners (i.e., CT + CTOV).

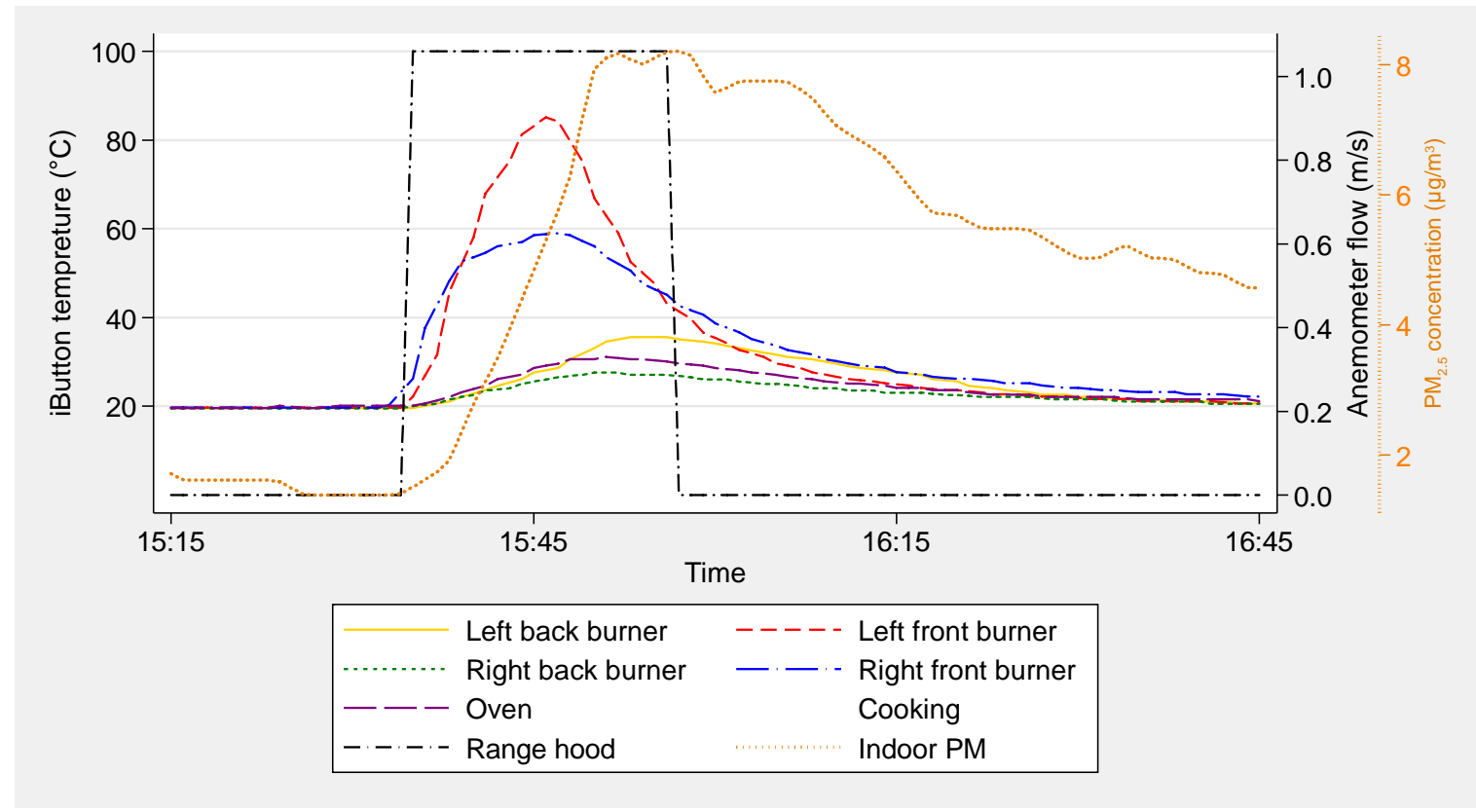

Figure 1. An example of full range hood use during a cooktop event with associated particulate matter emissions.

\subsection{Range Hood Operation}

Data from the anemometers and motor on-off loggers were reviewed to identify and develop a data table of hood use events. There were a few cases when the loggers indicated high-frequency intermittent use at low speeds that we interpreted as continuous hood use. The timing of range hood use and cooking were compared to determine the amount of hood use (if any) during each cooking event. We defined "full use" as the range hood starting within 3 min of the start of the cooking burner and being used for $>80 \%$ of the cooking time. Hood use was considered only if it overlapped in time with one or more cooking events; use that occurred independently of any cooking event was excluded from the analysis. In houses with OTRs, usage monitoring likely included incidences when the microwave was used to cook food and the fan was activated for that purpose, rather than for providing kitchen ventilation. The analysis only considered cooking events occurring during periods with valid range hood monitoring. Two apartments (identified as units 902 and 906 in the database) with range hoods operating continuously at low speed were excluded from the analysis. Three overnight uses of the oven in one apartment (unit 903) which were assumed to be done for heating, were also excluded from the analysis.

\section{4. $P M_{2.5}$ Event Identification}

$\mathrm{PM}_{2.5}$ emissions were identified by applying a machine learning approach called Random Forest (RF) to the time-resolved $\mathrm{PM}_{2.5}$ concentration measured in the living room of each home, as described in detail elsewhere [48]. Briefly, the RF model was originally developed using a training dataset where the indoor and outdoor $\mathrm{PM}_{2.5}$ concentrations were collected from 18 California low-income apartments [49]. The model uses data features calculated from the indoor and outdoor $\mathrm{PM}_{2.5}$ concentrations to identify indoor emission events. A large number of classification decision trees were generated to express the full possible sequences of features to characterize a data point. The predominant classification of all the 
decision trees becomes the final prediction of the RF model. In this study, the RF model was applied to 2-min running average $\mathrm{PM}_{2.5}$ data for both houses and apartments.

The $\mathrm{PM}_{2.5}$ emission events identified by the RF analysis were reviewed visually to correct any obvious errors in start and end times.

A $\mathrm{PM}_{2.5}$ emission event was linked to cooking if it started during a cooking event and the $\mathrm{PM}_{2.5}$ emission duration was no more than $5 \mathrm{~min}$ longer than the cooking duration. This window is applied to account for the uncertainty in PM emission event end times identified by the RF model, and also for the time lag between the start of an emission event and an increase in PM concentration measured by the photometer. If a cooking event overlapped with more than one emission event, all of the emission events were considered to be associated with the cooking event.

\subsection{Example Event Data}

Example data from an event are shown in Figure 1. Temperatures were measured adjacent to four cooktop burners and the oven under the cooktop. Range hood operation was monitored by an anemometer and indoor $\mathrm{PM}_{2.5}$ was measured in the living room. Two cooktop burners were used in this event. The right front burner was started at 15:32 and stopped on or before 15:47 and the left front burner was started at 15:34 and stopped on or before 15:46. Much smaller temperature rises recorded by sensors at the oven and other two cooktop burners are assumed to result from the two front burners. Range hood use was determined to start at 15:35 and end at 15:57 based on the measured anemometer flow rate. Because the delay between range hood start and cooking start was less than 3 min and the range hood was used through the rest of the cooking event, it was considered as a cooking event with full range hood use.

\subsection{Statistical Analysis}

We investigated the influence of cooking parameters, ventilation equipment, and household characteristics on the fraction of cooking events in each home that had coincident range hood use and/or the fraction of total events across all homes in each group-houses and apartments-that had range hood use during some or most of the duration of each cooking event. The investigated cooking parameters were cooktop or oven use, total minutes of burner use and whether there was an identifiable, substantial increase in $\mathrm{PM}_{2.5}$ coincident with burner use; the latter was assumed to indicate a particle-generating cooking event. The studied ventilation equipment characteristics were conventional range hood or over the range microwave (OTR) and measured airflow and rated sound for highest and lowest settings. Home and household characteristics included floor area, number of occupants, occupant density, air exchange rate (total, per square meter, and per occupant), presence of senior or child someone with health condition that is impacted by air pollution, formal education, income, satisfaction with indoor air quality, satisfaction with air movement indoors, vacuum frequency, window opening frequency, and self-reported reasons for not using range hoods (forget, not need, ineffective, noisy).

Associations between range hood use and potential explanatory parameters were assessed in three different ways. Pearson's chi-square test or Fisher's exact test was used for categorical binary variables (e.g., whether range hood used or not categorized by cooking type). Wilcoxon rank-sum tests were applied for continuous variables, such as burner minutes for cooking events, to assess if the distributions differed between groups of events differentiated by categorical variables, e.g., in which range hoods were used or not used. An analysis of variance (ANOVA) test was applied to check relationships between two continuous variables, e.g., range hood use rate in each home vs. floor area. Relationships are considered very likely when the $p$-value is $<0.05$ and likely when the $p$-value is between 0.05 and 0.1. For continuous variables such as cooking burner-min, Wilcoxon rank-sum tests were applied to assess if the distributions differed between groups of events differentiated by categorical variables (e.g., in which range hoods were used or not used). Statistical analyses were performed using Stata version 15 (StataCorp, LLC, College Station, TX, USA). 


\section{Results and Discussion}

\subsection{Frequency of Cooking}

Analysis of the iButton data found 607 cooking events in 57 single-family houses and 311 cooking events in 23 apartments. The distributions of total minutes of cooktop use and oven use per home per week at each hour of the day are shown in Figure 2 separately for houses and apartments. The mean and 10th-90th values of total cooking duration were 32 and 8-73 min for single-family houses and 40 and 8-56 min for apartments. In single family houses, the most cooking occurred during the late afternoon and evening (presumably around dinner) with a second mode during the morning, between 09:00 and 11:00. In apartments, cooking was more spread throughout the day with the peak occurring between 18:00 and 20:00.

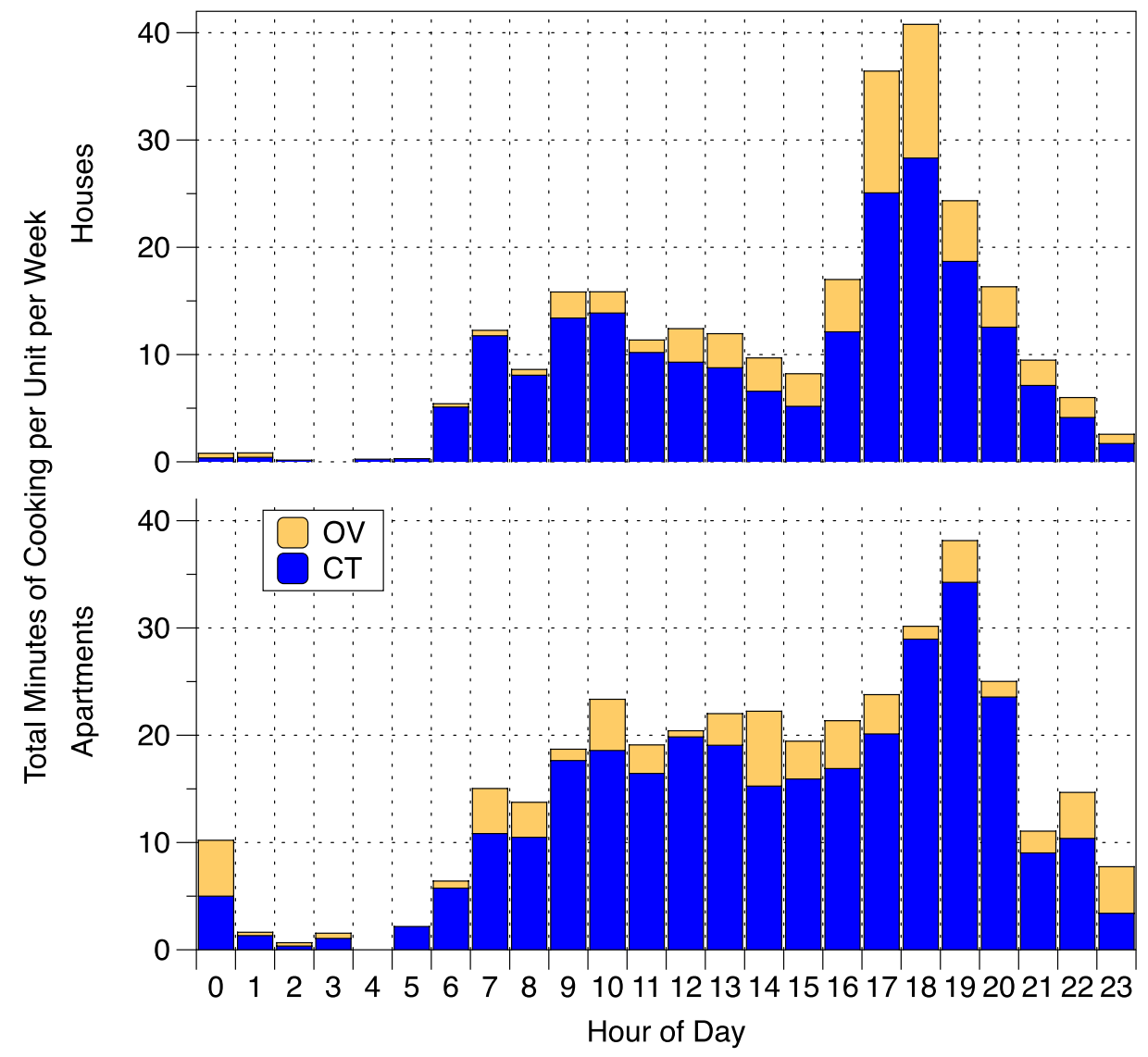

Figure 2. Distribution of total minutes of cooktop (CT) and oven (OV) use per home per week at each hour of the day in houses and apartments.

Subsequent analyses exclude cooking events that occurred when range hood use was not monitored, cooking events that occurred in apartments with a range hood operating continuously, and overnight oven use that was presumed to occur for heating. The remaining data included 784 cooking events, with 574 events in 54 houses and 210 events in 17 apartments.

\subsection{Fracion of Cooking Events with Range Hood Use by Home and Influencing Factors}

Figure 3 shows the number of cooking events with no range hood use, any use, and full use in each house or apartment. On average, occupants in the apartments cooked slightly more meals (median =9.0, mean $=12.4$ ) than occupants in the houses (median $=7.5$, mean $=10.6$ ) during the weeklong monitoring period. About one-third (32\%) of hood uses were considered full use, the remaining two-thirds of hood uses started with delays longer than $3 \mathrm{~min}$ and/or did not span $80 \%$ of the total cooking duration 
(see Tables S1 and S2 for more details). Of the 37 houses and 16 apartments with five or more cooking events, $49 \%$ of houses and $63 \%$ of apartments used the range hood for less than $30 \%$ of cooking events and only two of each type used the range hood during more than $70 \%$ of cooking events. The mean rate was indistinguishable in houses and apartments.

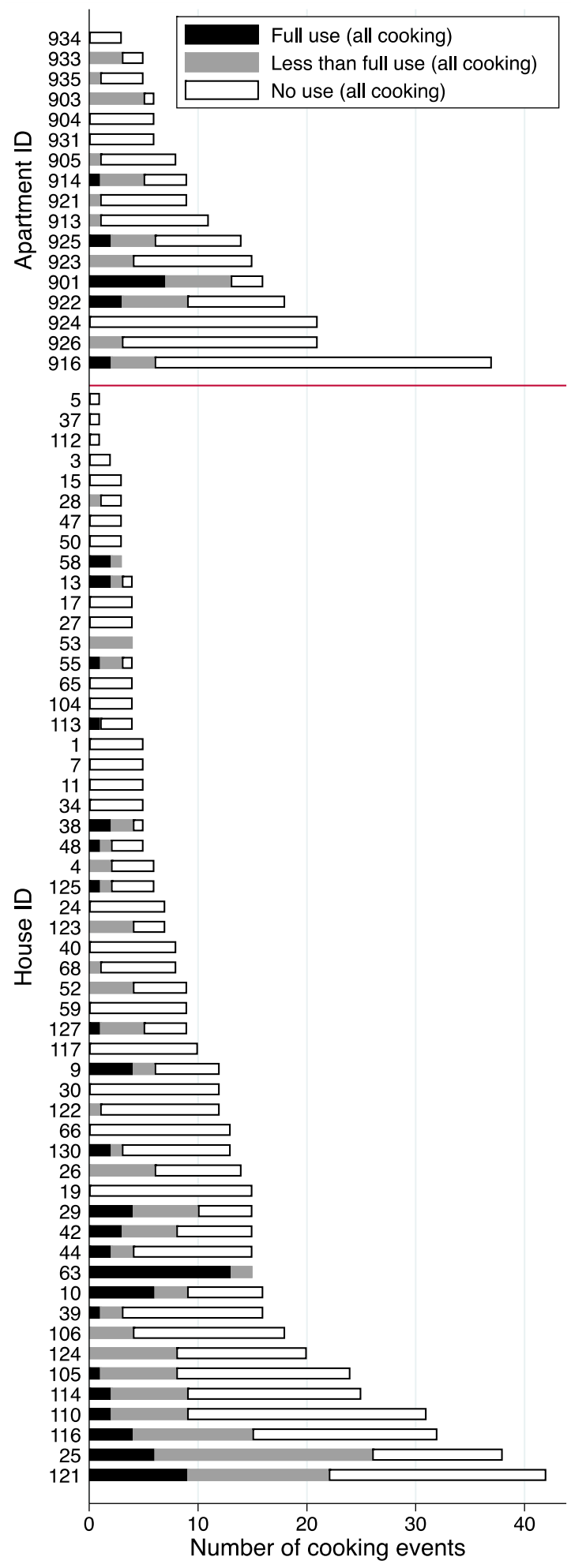

Figure 3. Range hood use for all cooking events by home. 
There were no statistically significant associations between the fraction of cooking events with range hood use by home (henceforth, "rate") and any ventilation equipment or household characteristics with analysis limited to homes with five or more cooking events (Table S3). Similar analyses examining relationships between equipment or home characteristics and the likelihood of a range hood being used across all the cooking events in all homes with data, found several significant associations, as indicated in Tables S4-S7. The most prominent factors were education and income level, with significantly higher rates of range hood use for cooking events in homes with higher income and education level. It is very important to note, however, that there were large and significant differences in education and of course income between the households in houses and the income-qualifying apartments. There also were statistically significant associations of lower range hood use when occupants were dissatisfied with air movement indoors $(p<0.01)$, open windows often $(<0.01)$ and report that their range hood was ineffective $(p<0.01)$. In houses, range hood usage was likely lower when occupants said they sometimes do not use the range hood because it is not needed $(p<0.01)$ or self-assessed that their range hood was ineffective $(p=0.02)$.

Table 1 shows that residents in houses used their range hoods more frequently than residents in apartments when cooking with a cooktop ( $p=0.006$ for CT only and $p=0.01$ for any CT). This difference may be connected to differences in range hood use by education and/or income level as noted previously. For example, residents in 46 out of 54 houses had bachelor degrees or higher, while only 2 out of 17 apartments had bachelor degrees or higher. Importantly, it is unclear which of the factors is driving higher rates of use, which could even be related to another factor that has not been quantified, e.g., the potential for a homeowner to select a preferred design or model of range hood or more familiarity with the equipment from a longer period of occupancy.

Table 1. Range hood use by cooking type.

\begin{tabular}{cccccc}
\hline \multirow{2}{*}{ Cooking Type } & \multicolumn{2}{c}{ Houses } & \multicolumn{2}{c}{ Apartments } & Cooking \\
\cline { 2 - 5 } & $\begin{array}{c}\text { Events } \\
\text { Any Hood Use } \\
\boldsymbol{n} \mathbf{( \% )}\end{array}$ & $\begin{array}{c}\text { Cooking } \\
\text { Events }\end{array}$ & $\begin{array}{c}\text { Any Hood Use } \\
\boldsymbol{n} \mathbf{( \% )}\end{array}$ & $\boldsymbol{p}$-Value ${ }^{\mathbf{1}}$ \\
\hline CT only & 487 & $182(37 \%)$ & 190 & $50(26 \%)$ & 0.006 \\
OV only & 48 & $12(25 \%)$ & 15 & $5(33 \%)$ & 0.53 \\
CTOV & 39 & $11(25 \%)$ & 5 & $3(60 \%)$ & 0.76 \\
Total & 574 & $205(36 \%)$ & 210 & $58(28 \%)$ & 0.03 \\
\hline$p$-value ${ }^{2}$ & 0.09 & 0.56 \\
\hline${ }^{1}$ Chi-square test for hood use comparing two home types: houses and apartments. ${ }^{2}$ Chi-square test for hood use \\
comparing two cooking types: CT only and OV only.
\end{tabular}

In houses with OTRs, some exhaust fan operation may result from automatic operation when microwaving food-with or without cooktop or conventional oven use-and thus not represent an intended use for ventilation. To investigate this, we repeated the analysis for houses with a regular range hood (i.e., not an OTR), and found the same result: residents in houses operated their standard range hoods more frequently than in apartments. No significant difference was observed in hood use between houses and apartments $(p=0.53)$ when cooking with the oven only. However, this finding is uncertain because there were very few cases of hood use during oven cooking events. Overall, the frequency of hood use during cooking with any burner was significantly higher $(p=0.03)$ in houses $(36 \%)$ than in apartments (28\%).

Table 1 shows that in single family house residents likely $(p=0.09)$ used a range hood or OTR more frequently when cooking with cooktop only, compared to oven only. In apartments, there was no discernible difference of range hood use with cooktop vs. oven use. Because ovens and cooktop burners can be used together in a cooking event, we compared full range hood use and any range hood use for different combinations of burner used, as shown in Tables S7-S10. The overall results confirmed 
that for single family houses, hood use was likely more frequent when residents used a cooktop burner either alone or together with an oven burner, compared to use of the oven alone or with a cooktop.

\subsection{Effect of Range Hood and Oven Type}

Unlike in the apartments, which all had a similar set up of a conventional range hood over a cooktop with gas oven underneath, configurations varied in single family houses. Among the 54 houses with valid cooking and range hood use data, some had a regular range hood $(n=22)$, while others had an OTR $(n=32)$. Some houses had ovens located underneath the range hood $(n=32)$, while others had separate ovens located off to a side $(n=22)$. Some houses had gas ovens, while others were electric (7 of 32 of the underneath ovens, and 21 of 22 the separate ovens were electric). Statistical tests were performed to see if these differences are associated with the frequency of range hood use. Table 2 shows no discernible effect of range hood type in single family houses for cooking events that involved cooktop only. Table 3 shows it was likely $(p=0.09)$ that more frequent hood use was associated with ovens located underneath the range hood ( $36 \%)$, compared to separate ovens located off to a side $(17 \%)$. However, this finding is uncertain because there were few cases of hood use when cooking with ovens. Additional analysis of hood use by oven location is provided in Table S11.

Table 2. Range hood use by range hood type in single family houses.

\begin{tabular}{ccc}
\hline Range Hood Type & $\begin{array}{c}\text { Cooking events-CT } \\
\text { Only }\end{array}$ & $\begin{array}{c}\text { Any Hood Use } \\
\boldsymbol{n} \mathbf{( \% )}\end{array}$ \\
\hline Regular range hood & 179 & $70(39 \%)$ \\
OTR microwave & 308 & $112(36 \%)$ \\
-value $^{1}$ & & 0.54 \\
\hline are test for hood use comparing two hood types: regular range hood and "over the range" (OTR).
\end{tabular}

Table 3. Range hood use by oven location in single family houses.

\begin{tabular}{ccc}
\hline Oven Location & $\begin{array}{c}\text { Cooking Events-OV } \\
\text { Only }\end{array}$ & $\begin{array}{c}\text { Any Hood Use } \\
\boldsymbol{n} \mathbf{( \% )}\end{array}$ \\
\hline Under range hood & 18 & $7(36 \%)$ \\
Off to a side $^{1}$-value $^{1}$ & 30 & $5(17 \%)$ \\
${ }^{1}$. & & 0.09 \\
\hline
\end{tabular}

${ }^{1}$ Chi-square test for hood use comparing the two types of oven location.

\subsection{Effect of Cooking Frequency}

Moderate correlation was found between the rate of any range hood use and the number of total cooking events or cooktop uses in each house (Spearman coefficient of $0.36, p<0.01$ for total cooking events). However, no correlation was found between the rate of any range hood use and the number of any cooking burner events or of cooktop events in apartments (Spearman coefficient of $0.09, p=0.73$ for total cooking events).

\subsection{Effect of Cooking Duration}

Table 4 shows that range hood use was more frequent when cooktop burners were used during longer events. In houses, range hoods or OTRs were operated during $52 \%$ of events when cooktop burners were used for more than 20 burner-minutes, compared to $33 \%$ for $11-20$ burner-minutes and $20 \%$ for $1-10$ burner-minutes. Apartment residents also used range hoods slightly more frequently when the cooktop was used more than for 20 burner-minutes, but the association between hood use and cooktop use duration was not statistically significantly $(p=0.45)$. We also applied the two-sample Wilcoxon rank-sum test to the house data by sorting the cooktop use durations into two groups: "Hood used" and "Hood not used". The mean ( \pm s.d.) cooktop use duration in houses was $35( \pm 34)$ minutes 
for the "Hood used" group, and the mean was $20( \pm 20)$ minutes for the "Hood not used" group. Cooktop use duration was significantly different between these two groups ( $p$-value $<0.01$ ). Applying the same analysis to data from apartments provides cooktop use durations of $29( \pm 41)$ minutes for the "Hood used" group and $23( \pm 22)$ minutes for the "Hood not used" group, with $p=0.38$ indicating that the two distributions are not likely different. For cooking events using ovens, no apparent relationship between hood use and oven use duration was found (Table S12).

Table 4. Range hood use by cooktop use duration.

\begin{tabular}{ccccc}
\hline \multirow{2}{*}{$\begin{array}{c}\text { Cooktop Use } \\
\text { (Burner-Minutes) }\end{array}$} & $\begin{array}{c}\text { Cooking } \\
\text { Events-CT Only }\end{array}$ & $\begin{array}{c}\text { Any Hood Use } \\
\boldsymbol{n} \mathbf{( \% )}\end{array}$ & $\begin{array}{c}\text { Cooking } \\
\text { events-CT Only }\end{array}$ & $\begin{array}{c}\text { Any Hood Use } \\
\boldsymbol{n} \mathbf{( \% )}\end{array}$ \\
\hline $1-10$ & 143 & $29(20 \%)$ & 60 & $14(23 \%)$ \\
$11-20$ & 139 & $46(33 \%)$ & 53 & $12(23 \%)$ \\
$>20$ & 205 & $107(52 \%)$ & 77 & $24(31 \%)$ \\
\hline$p$-value ${ }^{1}$ & \multicolumn{3}{c}{0.45} \\
\hline
\end{tabular}

\subsection{Relationship of Actual Range Hood Use to Self-Reported Use}

We compared actual range hood use and survey responses asking participants to self-report their range hood use habits in houses (Table 5) and apartments (Table 6). Note that the survey question and response options were somewhat different for the two studies. In the house study, participants were asked how frequently their range hood is used when cooking with a cooktop based on numerically-linked categories. In the apartment study, participants were asked about hood use during any cooking and given ordinal/categorical options. For consistency, Tables 5 and 6 only consider cooking with cooktop burners (i.e., "any $\mathrm{CT}^{\prime \prime}$ ). In both houses and apartments, actual hood use was higher in homes of participants that self-reported more frequent use, but actual use was much lower than self-reported use. For those reporting the most frequent range hood use-four or five out of five times in houses, or usually/always in apartments-actual hood use was only $45 \%$ and $36 \%$, respectively. The difference is statistically significant among the houses $(p<0.01)$, and likely so among the apartments $(p=0.10)$.

Table 5. Range hood use by self-reported use habit in houses.

\begin{tabular}{|c|c|c|c|c|c|}
\hline Survey Response ${ }^{1}$ & $\begin{array}{l}\text { Number of } \\
\text { Houses }\end{array}$ & $\begin{array}{c}\text { Cooking } \\
\text { Events-Any CT }\end{array}$ & $\begin{array}{c}\text { Any Hood Use } \\
n(\%)\end{array}$ & $\begin{array}{c}\text { Cooking } \\
\text { Events-All }\end{array}$ & $\begin{array}{c}\text { Any Hood Use } \\
n(\%)\end{array}$ \\
\hline $\begin{array}{l}\text { Always/most of time } \\
\text { ( } 4-5 \text { out of } 5 \text { times) }\end{array}$ & 26 & 349 & $158(45 \%)$ & 371 & $166(45 \%)$ \\
\hline $\begin{array}{c}\text { Sometimes } \\
\text { (2-3 out of } 5 \text { times) }\end{array}$ & 13 & 97 & $20(21 \%)$ & 109 & $22(20 \%)$ \\
\hline $\begin{array}{c}\text { Rarely/never } \\
\text { (0-1 out of } 5 \text { times) }\end{array}$ & 13 & 70 & $11(16 \%)$ & 83 & $13(16 \%)$ \\
\hline I don't know & 0 & 0 & 0 & 0 & 0 \\
\hline No response & 2 & 10 & $4(40 \%)$ & 11 & $4(36 \%)$ \\
\hline$p$-value ${ }^{2}$ & & \multicolumn{2}{|c|}{$<0.01$} & \multicolumn{2}{|c|}{$<0.01$} \\
\hline
\end{tabular}

${ }^{1}$ Survey question: How often is a kitchen range hood or exhaust fan used when cooking with a cooktop? ${ }^{2}$ Chi-square test with 1-side Fisher exact value for hood use comparing different survey responses. 
Table 6. Range hood use by self-reported use habit in apartments.

\begin{tabular}{cccccc}
\hline Survey Responses & $\begin{array}{c}\text { Number of } \\
\text { Apartments }\end{array}$ & $\begin{array}{c}\text { Cooking } \\
\text { Events-Any CT }\end{array}$ & $\begin{array}{c}\text { Any Hood Use } \\
\boldsymbol{n}(\%)\end{array}$ & $\begin{array}{c}\text { Cooking } \\
\text { Events-All }\end{array}$ & $\begin{array}{c}\text { Any Hood Use } \\
\boldsymbol{n}(\%)\end{array}$ \\
\hline Usually or always & 6 & 83 & $32(39 \%)$ & 92 & $33(36 \%)$ \\
Sometimes/as needed & 6 & 51 & $10(20 \%)$ & 57 & $14(25 \%)$ \\
Rarely or never & 0 & 0 & 0 & 0 & 0 \\
I don't know & 3 & 46 & $6(13 \%)$ & 46 & $6(13 \%)$ \\
No response & 2 & 15 & $5(33 \%)$ & 15 & $5(33 \%)$ \\
\hline$p$-value & & \multicolumn{3}{c}{0.10} \\
\hline
\end{tabular}

${ }^{1}$ Survey question: How often is the range hood or exhaust fan used when cooking? ${ }^{2}$ Chi-square test with 1-side Fisher exact value for hood use comparing the within first three survey responses.

To further elucidate if occupants are reliable reporters of range hood use, Figure 4 presents actual range hood use by self-reported hood use in houses and apartments. Actual hood use frequency was higher among households that reported to use their range hood most frequently, but there was wide variability and actual hood use was much less frequent than reported. This result indicates large bias when actual range hood use is estimated based on self-reporting in a survey.
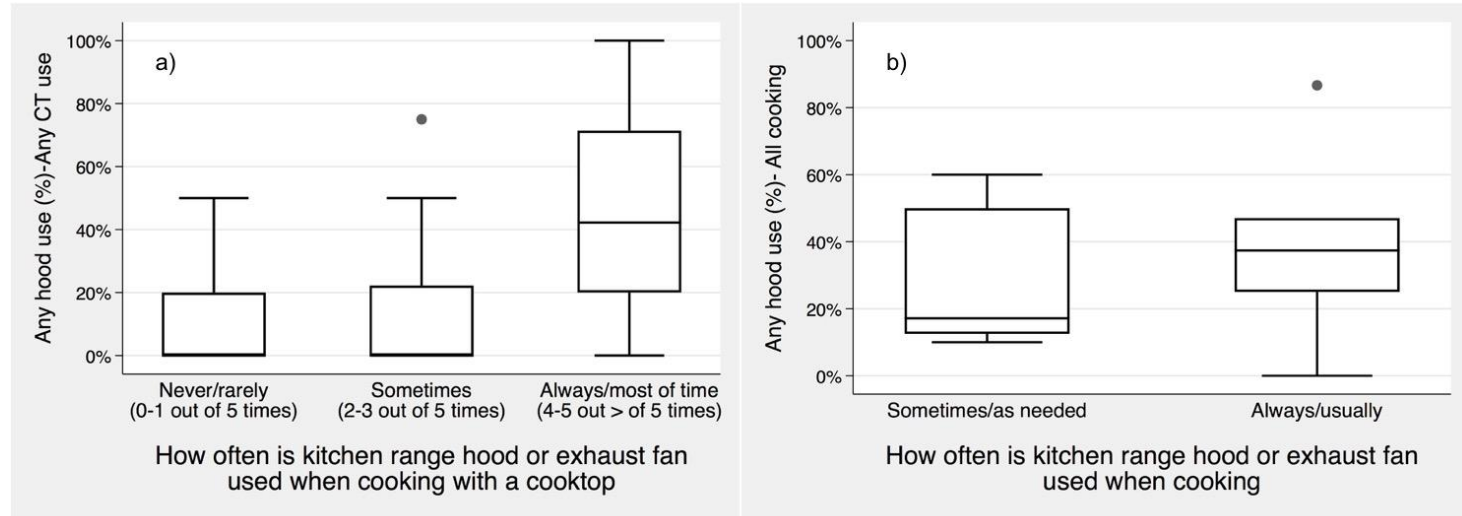

Figure 4. Distribution of range hood use in each home grouped by survey responses for (a) houses (any CT) and (b) apartments (all cooking types). Boxes show interquartile range (IQR), whiskers are limit values within 75th $+1.5 \mathrm{IQR}$ and 25 th $-1.5 \mathrm{IQR}$, and circles show all data outside of whiskers.

Table 7 shows range hood use by cooktop burner-minutes and self-reported habits in all homes. These data reinforce the associations found between hood use frequency with both cooktop use duration and self-reported habits. Participants who claimed to use their range hoods always or most of the time actually used them about $60 \%$ of the time when using their cooktop for longer than 20 burner-minutes. However, the same households used their range hoods only $38 \%$ of the time when using their cooktop for 11-20 burner-minutes, and $26 \%$ of the time for 10 burner-minutes or less. Significant differences of actual hood use were found between the groups of households with different self-reported habits regardless of cooktop duration. For all levels of self-reported use, actual range hood use was significantly higher as cooktop use duration increased; this represents a rational prioritization to use the control more frequently as the potential hazard increases. 
Table 7. Range hood use by self-reported use habits and cooktop use duration.

\begin{tabular}{|c|c|c|c|c|c|c|c|c|c|c|c|c|c|}
\hline \multirow[b]{2}{*}{$\begin{array}{c}\text { Cooktop Use } \\
\text { (Burner-Minutes) }\end{array}$} & \multicolumn{3}{|c|}{ All Survey Responses } & \multicolumn{3}{|c|}{$\begin{array}{l}\text { Never or Rarely } \\
(0-1 \text { of } 5 \text { Times })\end{array}$} & \multicolumn{3}{|c|}{$\begin{array}{l}\text { Sometimes or as Needed } \\
\text { (2-3 of } 5 \text { Times) }\end{array}$} & \multicolumn{3}{|c|}{$\begin{array}{l}\text { Always/Usually or most of the Time } \\
\text { (4-5 of } 5 \text { Times) }\end{array}$} & \multirow[b]{2}{*}{$p$-Value ${ }^{2}$} \\
\hline & $\begin{array}{c}\text { Cooktop } \\
\text { Events-CT } \\
\text { Only }\end{array}$ & $\begin{array}{l}\text { Any } \\
\text { Hood } \\
\text { Use } \\
\end{array}$ & $\%$ Use & $\begin{array}{c}\text { Cooktop } \\
\text { Events-CT } \\
\text { Only }\end{array}$ & $\begin{array}{c}\text { Any } \\
\text { Hood } \\
\text { Use } \\
\end{array}$ & $\%$ Use & $\begin{array}{c}\text { Cooktop } \\
\text { Events-CT } \\
\text { Only }\end{array}$ & $\begin{array}{c}\text { Any } \\
\text { Hood } \\
\text { Use }\end{array}$ & $\%$ Use & $\begin{array}{c}\text { Cooktop } \\
\text { Events-CT } \\
\text { Only }\end{array}$ & $\begin{array}{l}\text { Any Hood } \\
\text { Use }\end{array}$ & $\%$ Use & \\
\hline $1-10$ & 194 & 41 & $21 \%$ & 20 & 0 & $0 \%$ & 41 & 6 & $15 \%$ & 133 & 35 & $26 \%$ & 0.01 \\
\hline $11-20$ & 175 & 55 & $31 \%$ & 20 & 5 & $25 \%$ & 42 & 7 & $17 \%$ & 113 & 43 & $38 \%$ & 0.03 \\
\hline$>20$ & 241 & 121 & $50 \%$ & 24 & 6 & $25 \%$ & 50 & 14 & $28 \%$ & 167 & 101 & $60 \%$ & $<0.01$ \\
\hline$p$-value ${ }^{1}$ & & $<0.01$ & & & 0.03 & & & 0.22 & & & $<0.01$ & & \\
\hline
\end{tabular}

${ }^{1} p$-value was calculated using Chi-square test for Any hood use among three burner-use duration groups within same response. ${ }^{2} p$-value was calculated using Chi-square test for Any hood use among three groups with different responses within same burner mins. 


\section{7. $P M_{2.5}$ Emissions and Range Hood Use}

There were $403 \mathrm{PM}_{2.5}$ emission events identified for houses and 281 for apartments. Emission events varied vastly by duration and intensity, but the central tendency and range of values were similar among the houses and the apartments. The median $\mathrm{PM}_{2.5}$ emission duration was 16 min for the houses, and $14 \mathrm{~min}$ for the apartments. The 5th and 95th percentiles of $\mathrm{PM}_{2.5}$ emission duration were 10 and $42 \mathrm{~min}$ for the houses, and 4 and $52 \mathrm{~min}$ for the apartments. The highest 5 -min $\mathrm{PM}_{2.5}$ concentration during emissions had a median value of $36 \mu \mathrm{g} / \mathrm{m}^{3}$ for the houses, and $37 \mu \mathrm{g} / \mathrm{m}^{3}$ for the apartments. The 5th and 95th percentiles of the highest 5-min $\mathrm{PM}_{2.5}$ concentration were 9 and $310 \mu \mathrm{g} / \mathrm{m}^{3}$ for the houses, and 9 and $250 \mu \mathrm{g} / \mathrm{m}^{3}$ for the apartments. We note the possibility that use of a range hood with high capture efficiency for particles theoretically could result in no substantial increase in $\mathrm{PM}_{2.5}$ in the space and thus no identified event. Limited data on range hood effectiveness for particles generated during cooking suggest that high capture could result when cooking at low to medium heat on the back burner, but not when cooking at high heat on a front burner [27].

Roughly $25 \%$ of cooking events in houses and $20 \%$ in apartments were linked with $\mathrm{PM}_{2.5}$ emissions (Table 8). In houses, a range hood was used for $58 \%$ of the cooking events with $\mathrm{PM}_{2.5}$ emission, and this was substantially and statistically significantly $(p<0.01)$ higher than range hood use when there was no $\mathrm{PM}_{2.5}$ emission detected (30\%). In apartments, slightly higher use of range hoods when $\mathrm{PM}_{2.5}$ accompanied cooking ( $34 \%$ compared to $26 \%$ ) was not statistically significant $(p=0.40)$.

Table 8. Range hood use by cooking events with and without fine particulate matter $\left(\mathrm{PM}_{2.5}\right)$ emissions.

\begin{tabular}{|c|c|c|c|c|}
\hline \multirow[b]{2}{*}{$\mathbf{P M}_{2.5}$ Emissions } & \multicolumn{2}{|c|}{ House } & \multicolumn{2}{|c|}{ Apartment } \\
\hline & Cooking Events & $\begin{array}{c}\text { Any Hood Use } \\
(\%)\end{array}$ & Cooking Events & $\begin{array}{c}\text { Any Hood Use } \\
n(\%)\end{array}$ \\
\hline Yes & 115 & $67(58 \%)$ & 41 & $14(34 \%)$ \\
\hline No & 459 & $138(30 \%)$ & 169 & $44(26 \%)$ \\
\hline$p$-value ${ }^{1}$ & & $<0.01$ & & 0.33 \\
\hline
\end{tabular}

${ }^{1}$ Chi-square test for hood use frequency comparing cooking events with and without PM emissions.

Cooking events with associated $\mathrm{PM}_{2.5}$ emissions were categorized into two groups based on the peak 5-min $\mathrm{PM}_{2.5}$ concentration during emissions, and the association of this metric with range hood use is reported in Table 9. Higher peak $\mathrm{PM}_{2.5}$ concentrations could result from events with higher mass emissions, similar emissions being emitted into smaller spaces (noting that apartments are systematically smaller than houses), and/or slower mixing within larger homes. In houses, range hood use did not vary with the peak 5-min $\mathrm{PM}_{2.5}$ concentration. In apartments, however, range hood use was more frequent $(56 \%)$ when the peak $5-\mathrm{min} \mathrm{PM}_{2.5}$ concentration exceeded $50 \mu \mathrm{g} / \mathrm{m}^{3}$, compared to only $28 \%$ when otherwise. But the differences were not statistically significant due to limited data. A possible reason for range hoods to be used less often in apartments when peak $\mathrm{PM}_{2.5}$ concentrations are lower is that emissions must be much smaller for peak concentrations to remain low in the apartments, which have much smaller volumes compared with houses; the smaller emission sources may not be as noticeable to residents.

Our analysis indicates that residents in single family houses used range hoods more often when cooking caused a discernible increase in $\mathrm{PM}_{2.5}$. In apartments, residents used their range hood more often only if high concentrations of $\mathrm{PM}_{2.5}\left(50 \mu \mathrm{g} / \mathrm{m}^{3}\right)$ were generated during cooking. Even though we do not have additional information to explain this subtle difference in range hood use between houses and apartments, overall these results indicate that occupants in both types of homes took actions to address cooking emissions. 
Table 9. Range hood use by cooking events with $\mathrm{PM}_{2.5}$ emissions.

\begin{tabular}{ccccc}
\hline \multirow{2}{*}{$\begin{array}{c}\text { Highest 5-min } \\
\mathbf{P M}_{\mathbf{2 . 5}}>\mathbf{5 0} \boldsymbol{\mu g} / \mathbf{m}^{\mathbf{3}}\end{array}$} & $\begin{array}{c}\text { Cooking } \\
\text { Events }\end{array}$ & $\begin{array}{c}\text { Any Hood Use } \\
\boldsymbol{n} \mathbf{( \% )}\end{array}$ & $\begin{array}{c}\text { Cooking } \\
\text { Events }\end{array}$ & $\begin{array}{c}\text { Any Hood Use } \\
\boldsymbol{n} \mathbf{( \% )}\end{array}$ \\
\hline Yes & 58 & $30(52 \%)$ & 9 & $5(56 \%)$ \\
\hline No & 57 & $37(65 \%)$ & 32 & $9(28 \%)$ \\
\hline$p$-value & & 0.19 & & 0.23 \\
\hline
\end{tabular}

${ }^{1}$ Chi-square test for hood use frequency comparing cooking events with peak PM below or above $50 \mu \mathrm{g} / \mathrm{m}^{3}$.

\subsection{Limitations}

A key limitation of our study is that the sample was not randomly drawn from the population, so findings may not apply more broadly. Our analysis was based solely on households living either in owner occupied houses that were built in recent years, or tenant occupied apartments that had been built or renovated in recent years. Relative to the general population of California, the households in the single, detached houses were skewed toward higher income and higher education as reported previously [44], while the apartments were recruited within low-income communities. The sample was not recruited to represent the diversity of cooking practices or even the diversity of cultures within California or the US. In addition, all of the households included someone that volunteered to participate for a one-week indoor air quality study, indicating at least a possibility for greater interest and attentiveness to IAQ hazards and controls than occurs in the general population.

Another important limitation is the small sample size, which limits the discernibility of some potential predictors that correlate with range hood use. In most cases, the relationship between range hood use and a factor was analyzed independently, rather than considering all the different factors together. We are limited by the small dataset to explore how all these factors in aggregation impact range hood use in homes.

The methods used to identify the start and stop times of cooking and range hood use were imprecise; this could have caused some errors in characterizing full or partial range hood use. Despite our best effort to visually inspect and correct the identification of cooking events, some ambiguity in the data remains. For example, it is difficult to estimate burner-minutes for cooking events that involved multiple burners. Future studies that can more precisely and certainly define cooking activities and link those to range hood use would advance understanding of how this residential IAQ control is used.

The linking of $\mathrm{PM}_{2.5}$ emission events to temporally proximate cooking events was uncertain because the source of $\mathrm{PM}_{2.5}$ may not be cooking related. The photometers used in the house and apartment studies were calibrated using a limited number of gravimetric filters that were collected. However, even after this calibration step, the adjusted $\mathrm{PM}_{2.5}$ measurements may have missed some cooking emissions, such as if the emitted particles were predominantly too small in diameter for the photometer to measure $[20,50,51]$. Future studies that confirm when PM is associated with cooking emissions would help in the understanding of how rationally people use their range hoods to control potentially hazardous contaminants.

\section{Conclusions}

We investigated range hood use for 784 cooking events in 71 homes including 54 single family houses and 17 low-income apartments constructed or renovated in recent years. Range hood use occurred more frequently with cooking in single family houses $(36 \%)$ than in the apartments $(28 \%)$. Range hood use by home generally increased with cooking frequency. In both houses and apartments, range hood use increased with cooktop use duration, but not with oven use duration. Participants who self-reported frequent use actually used their hoods more frequently; however, actual use was much lower than self-reported, with only $45 \%$ and $36 \%$ actual range hood use in houses and apartments 
where occupants self-reported use of always, usually, or most of the time. Residents in single family houses used range hoods more often when cooking events generated any level of $\mathrm{PM}_{2.5}$. In apartments, residents used the range hood more often only if high concentrations of particles were generated during cooking.

A better understanding of how range hoods are currently used in homes will help inform the potential benefits of adding sensing for automatic operation and improving awareness that range hoods should be used to reduce the population health burden from cooking emissions. The findings from this analysis are useful bases for future studies that aim to measure the impact of range hood use in reducing occupant exposure to indoor air pollutants in their homes.

Supplementary Materials: The following are available online at http://www.mdpi.com/1660-4601/17/23/8870/s1: Table S1. Time delays in range hood start, Table S2. Range hood use duration as a percentage of cooking time, Table S3. Investigation of associations between equipment and home characteristics and rate of range hood use by home, for houses and apartments, Table S4. Investigation of associations between household characteristics and rate of range hood use across all the cooking events for all homes, Table S5. Investigation of associations between household characteristics and rate of range hood use across all the cooking events for houses only, Table S6. Investigation of associations between household characteristics and rate of range hood use across all the cooking events for apartment only, Table S7. Range hood use by cooking type: Any cooktop use vs. only oven use 4, Table S8. Range hood use by cooking type: Only cooktop use vs. any oven use, Table S9. Range hood use by cooking type: Only cooktop use vs. only oven use, Table S10. Range hood use by cooking type: Any cooktop use vs. any oven use, Table S11. Range hood use by cooking type for houses with ovens located underneath the range hood, Table S12. Range hood use by oven use duration.

Author Contributions: Conceptualization, B.C.S. and W.R.C.; methodology, W.R.C., H.Z., B.C.S., W.W.D., H.T., Walker; formal analysis, H.Z., W.R.C., W.W.D., H.T.; investigation, W.R.C., H.Z., B.C.S., W.W.D., H.T.; data curation, H.Z., W.W.D., W.R.C.; writing-original draft preparation, H.Z., B.C.S., W.R.C.; writing-review and editing, H.Z., W.R.C., I.S.W., B.C.S.; visualization, H.Z., W.W.D., W.R.C.; supervision, B.C.S., W.R.C., I.S.W.; project administration, B.C.S.; funding acquisition, B.C.S., W.R.C., I.S.W. All authors have read and agreed to the published version of the manuscript.

Funding: This research was supported by the California Energy Commission via Contract PIR-16-012, the U.S. Department, Building Technologies Office, via Contract DE-AC02-05CH11231, and the U.S. Environmental Protection Agency via Interagency Agreement DW-89-9232201-7.

Acknowledgments: The authors appreciate the contribution of Yang-Seon Kim, who did the first compilation of data from houses. We are also deeply appreciative of the study participants.

Conflicts of Interest: The authors declare no conflict of interest.

\section{References}

1. Wallace, L.; Wang, F.; Howard-Reed, C.; Persily, A. Contribution of gas and electric stoves to residential ultrafine particle concentrations between 2 and $64 \mathrm{~nm}$ : Size distributions and emission and coagulation remission and coagulation rates. Environ. Sci. Technol. 2008, 42, 8641-8647. [CrossRef] [PubMed]

2. Dennekamp, M. Ultrafine particles and nitrogen oxides generated by gas and electric cooking. Occup. Environ. Med. 2001, 58, 511-516. [CrossRef] [PubMed]

3. Moschandreas, D.J.; Relwani, S.M. Field-measurements of NO2 gas range-top burner emission rates. Environ. Int. 1989, 15, 489-492. [CrossRef]

4. Wallace, L.A.; Emmerich, S.J.; Howard-Reed, C. Source Strengths of Ultrafine and Fine Particles Due to Cooking with a Gas Stove. Environ. Sci. Technol. 2004, 38, 2304-2311. [CrossRef]

5. Mullen, N.A.; Li, J.; Russell, M.L.; Spears, M.; Less, B.D.; Singer, B.C. Results of the California Healthy Homes Indoor Air Quality Study of 2011-2013: Impact of natural gas appliances on air pollutant concentrations. Indoor Air 2016, 26, 231-245. [CrossRef]

6. Less, B.; Mullen, N.; Singer, B.; Walker, I. Indoor air quality in 24 California residences designed as high-performance homes. Sci. Technol. Built Environ. 2015, 21, 14-24. [CrossRef]

7. Singer, B.C.; Apte, M.G.; Black, D.R.; Hotchi, T.; Lucas, D.; Lunden, M.M.; Mirer, A.G.; Spears, M.; Sullivan, D.P. Natural Gas Variability in California: Environmental Impacts and Device Performance: Experimental Evaluation of Pollutant Emissions from Residential Appliances; California Energy Commission: Sacramento, CA, USA, 2010. 
8. Logue, J.M.; Klepeis, N.E.; Lobscheid, A.B.; Singer, B.C. Pollutant Exposures from Natural Gas Cooking Burners: A Simulation-Based Assessment for Southern California. Environ. Health Perspect. 2014, 122, 43-50. [CrossRef]

9. Singer, B.C.; Pass, R.Z.; Delp, W.W.; Lorenzetti, D.M.; Maddalena, R.L. Pollutant concentrations and emission rates from natural gas cooking burners without and with range hood exhaust in nine California homes. Build. Environ. 2017, 122, 215-229. [CrossRef]

10. Belanger, K.; Holford, T.R.; Gent, J.F.; Hill, M.E.; Kezik, J.M.; Leaderer, B.P. Household Levels of Nitrogen Dioxide and Pediatric Asthma Severity. Epidemiology 2013, 24, 320-330. [CrossRef]

11. Lin, W.W.; Brunekreef, B.; Gehring, U. Meta-analysis of the effects of indoor nitrogen dioxide and gas cooking on asthma and wheeze in children. Int. J. Epidemiol. 2013, 42, 1724-1737. [CrossRef] [PubMed]

12. Abdullahi, K.L.; Delgado-Saborit, J.M.; Harrison, R.M. Emissions and indoor concentrations of particulate matter and its specific chemical components from cooking: A review. Atmos. Environ. 2013, 71, 260-294. [CrossRef]

13. Buonanno, G.; Morawska, L.; Stabile, L. Particle emission factors during cooking activities. Atmos. Environ. 2009, 43, 3235-3242. [CrossRef]

14. Fortmann, R.; Kariher, P.; Clayton, R. Indoor Air Quality: Residential Cooking Exposures; Prepared for California Air Resources Board: Sacramento, CA, USA, 2001.

15. Fullana, A.; Carbonell-Barrachina, A.A.; Sidhu, S. Volatile aldehyde emissions from heated cooking oils. J. Sci. Food Agric. 2004, 84, 2015-2021. [CrossRef]

16. Seaman, V.Y.; Bennett, D.H.; Cahill, T.M. Indoor acrolein emission and decay rates resulting from domestic cooking events. Atmos. Environ. 2009, 43, 6199-6204. [CrossRef]

17. Zhang, Q.F.; Gangupomu, R.H.; Ramirez, D.; Zhu, Y.F. Measurement of ultrafine particles and other air pollutants emitted by cooking activities. Int. J. Environ. Res. Public Health 2010, 7, 1744-1759. [CrossRef]

18. Zhao, Y.J.; Zhao, B. Emissions of air pollutants from Chinese cooking: A literature review. Build. Simul. 2018, 11, 977-995. [CrossRef]

19. Torkmahalleh, M.A.; Gorjinezhad, S.; Unluevcek, H.S.; Hopke, P.K. Review of factors impacting emission/concentration of cooking generated particulate matter. Sci. Total Environ. 2017, 586, 1046-1056. [CrossRef]

20. Chen, W.; Wang, P.; Zhang, D.; Liu, J.; Dai, X. The impact of water on particle emissions from heated cooking oil. Aerosol Air Qual. Res. 2020, 20, 533-543. [CrossRef]

21. US EPA. Final Report: Integrated Science Assessment for Particulate Matter; U.S. Environmental Protection Agency: Washington, DC, USA, 2009.

22. Yu, I.T.S.; Chiu, Y.L.; Au, J.S.K.; Wong, T.W.; Tang, J.L. Dose-response relationship between cooking fumes exposures and lung cancer among Chinese nonsmoking women. Cancer Res. 2006, 66, 4961-4967. [CrossRef]

23. Liu, S.; Dong, J.; Cao, Q.; Zhou, X.; Li, J.; Lin, X.; Qing, K.; Zhang, W.; Chen, Q. Indoor thermal environment and air quality in Chinese-style residential kitchens. Indoor Air 2020, 30, 198-212. [CrossRef]

24. Delp, W.W.; Singer, B.C. Performance assessment of US residential cooking exhaust hoods. Environ. Sci. Technol. 2012, 46, 6167-6173. [CrossRef] [PubMed]

25. Rim, D.; Wallace, L.; Nabinger, S.; Persily, A. Reduction of exposure to ultrafine particles by kitchen exhaust hoods: The effects of exhaust flow rates, particle size, and burner position. Sci. Total Environ. 2012, 432, 350-356. [CrossRef] [PubMed]

26. Singer, B.C.; Delp, W.W.; Price, P.N.; Apte, M.G. Performance of installed cooking exhaust devices. Indoor Air 2012, 22, 224-234. [CrossRef] [PubMed]

27. Lunden, M.M.; Delp, W.W.; Singer, B.C. Capture efficiency of cooking-related fine and ultrafine particles by residential exhaust hoods. Indoor Air 2015, 25, 45-58. [CrossRef] [PubMed]

28. Zhao, Y.; Zhao, B. Reducing human exposure to PM2.5 generated while cooking typical Chinese cuisine. Build. Environ. 2020, 168, 106522. [CrossRef]

29. Dobbin, N.A.; Sun, L.; Wallace, L.; Kulka, R.; You, H.Y.; Shin, T.; Aubin, D.; St-Jean, M.; Singer, B.C. The benefit of kitchen exhaust fan use after cooking-An experimental assessment. Build. Environ. 2018, 135, 286-296. [CrossRef] 
30. O'Leary, C.; de Kluizenaar, Y.; Jacobs, P.; Borsboom, W.; Hall, I.; Jones, B. Investigating measurements of fine particle (PM2.5) emissions from the cooking of meals and mitigating exposure using a cooker hood. Indoor Air 2019, 29, 423-438. [CrossRef]

31. U.S. Energy Information Administration Residential Energy Consumption Survey (RECS). Available online: https://www.eia.gov/consumption/residential/index.php (accessed on 17 July 2020).

32. California Energy Commission. Residental Appliance Saturation Study. 2019. Available online: https://www. energy.ca.gov/data-reports/surveys/2019-residental-appliance-saturation-study (accessed on 17 July 2020).

33. Bradman, A.; Chevrier, J.; Tager, I.; Lipsett, M.; Sedgwick, J.; Macher, J.; Vargas, A.B.; Cabrera, E.B.; Camacho, J.M.; Weldon, R.; et al. Association of housing disrepair indicators with cockroach and rodent infestations in a cohort of pregnant Latina women and their children. Environ. Health Perspect. 2005, 113, 1795-1801. [CrossRef]

34. Piazza, T.; Lee, R.; Sherman, M.; Price, P. Study of Ventilation Practices and Household Characteristics in New California Homes. Final Report for Energy Commission Contract 500-02-023 and ARB Contract 03-026.; California Energy Commission and California Air Resources Board: Sacramento, CA, USA, 2007.

35. Chan, W.R.; Kim, Y.-S.; Less, B.D.; Singer, B.C.; Walker, I.S. Ventilation and Indoor Air Quality in New California Homes with Gas Appliances and Mechanical Ventilation; Lawrence Berkeley National Laboratory: Berkeley, CA, USA, 2019.

36. ANSI/ASHRAE. Ventilation and Indoor Air Quality in Residential Buildings, Standard 62.2-2019; ASHRAE: Atlanta, GA, USA, 2019.

37. Energy Star. Program Requirements for Residential Ventilating Fans; U.S. Environmental Protection Agency: Washington, DC, USA, 2018.

38. International Code Council. International Mechanical Code; International Code Council, Inc.: Country Club Hills, IL, USA, 2017; ISBN 978-1-60983-735-8.

39. International Code Council. International Energy Conservation Code; International Code Council, Inc.: Country Club Hills, IL, USA, 2017; ISBN 978-1-60983-749-5.

40. California Energy Commission. Building Energy Efficiency Standards; California Energy Commission: Sacramento, CA, USA, 2008.

41. Holm, S.M.; Balmes, J.; Gillette, D.; Hartin, K.; Seto, E.; Lindeman, D.; Polanco, D.; Fong, E. Cooking behaviors are related to household particulate matter exposure in children with asthma in the urban East Bay Area of Northern California. PLoS ONE 2018, 13, e0197199. [CrossRef]

42. Klug, V.L.; Singer, B.C.; Bedrosian, T.; D'Cruz, C. Characteristics of Range Hoods in California Homes-Data Collected from a Real Estate Web Site LBNL-5067E; Berkeleyca Lawrence Berkeley National Lab: California, CA, USA, 2011.

43. Liu, S.; Wallace, L. Residential cooking and kitchen ventilation behaviors and the impact on exposure. JAWMA Rev. 2020. [CrossRef]

44. Singer, B.C.; Chan, W.R.; Kim, Y.-S.; Offermann, F.J.; Walker, I.S. Indoor Air Quality in California Homes with Code-Required Mechanical Ventilation. Indoor Air 2020. [CrossRef] [PubMed]

45. Chan, W.; Kim, Y.-S.; Delp, W.; Walker, I.; Singer, B. Data from: Indoor air quality in California homes with code-required mechanical ventilation. Dryad 2020. [CrossRef]

46. Zhao, H.; Chan, W.; Cohn, S.; Delp, W.W.; Walker, I.S.; Singer, B.C. Indoor air quality in new and renovated low-income apartments with mechanical ventilation and natural gas cooking in California. Dryad 2020. [CrossRef] [PubMed]

47. Zhao, H.; Chan, W.R.; Cohn, S.; Delp, W.W.; Walker, I.S.; Singer, B.C. Indoor Air Quality in New and Renovated Low-Income Apartments with Mechanical Ventilation and Natural Gas Cooking in California. Indoor Air 2020. [CrossRef]

48. Tang, H.; Chan, W.R.; Sohn, M. Automating the interpretation of PM 2.5 time-resolved measurements using a data-driven approach. Indoor Air under Rev. 2019, 12, 69.

49. Chan, W.R.; Logue, J.M.; Wu, X.; Klepeis, N.E.; Fisk, W.J.; Noris, F.; Singer, B.C. Quantifying fine particle emission events from time-resolved measurements: Method description and application to 18 California low-income apartments. Indoor Air 2018, 28, 89-101. [CrossRef] 
50. Wang, Z.; Delp, W.W.; Singer, B.C. Performance of low-cost indoor air quality monitors for PM2.5 and PM10 from residential sources. Build. Environ. 2020, 171, 106654. [CrossRef]

51. Singer, B.C.; Delp, W.W. Response of consumer and research grade indoor air quality monitors to residential sources of fine particles. Indoor Air 2018, 28, 624-639. [CrossRef]

Publisher's Note: MDPI stays neutral with regard to jurisdictional claims in published maps and institutional affiliations.

(C) 2020 by the authors. Licensee MDPI, Basel, Switzerland. This article is an open access article distributed under the terms and conditions of the Creative Commons Attribution (CC BY) license (http://creativecommons.org/licenses/by/4.0/). 